Supporting information:

\title{
The Bacillus subtilis spore inner membrane proteome
}

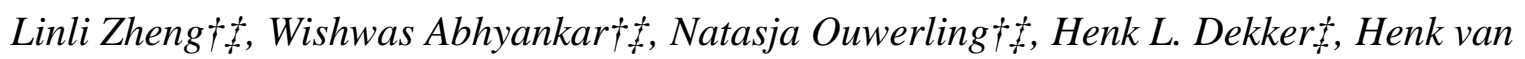

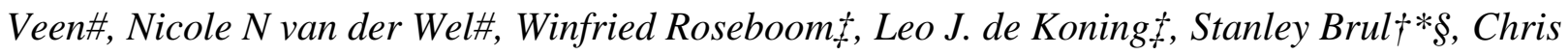
G. de Koster†*§

$†$ Molecular Biology \& Microbial Food Safety; $¥$ Mass Spectrometry of Biomacromolecules, Swammerdam Institute for Life Sciences, University of Amsterdam, Amsterdam, The Netherlands; \# Electron Microscopy Centre Amsterdam, Department of Cell Biology and Histology, Academic Medical Center, Amsterdam, The Netherlands.

\section{Corresponding Author}

*C.G.d.K.: E-mail: c.g.dekoster@uva.nl. Tel.: +31 (0)205255457.

*S.B.: E-mail: s.brul@uva.nl. Tel.: +31 (0)205257079

\section{Table of contents}

Table S1: Proteins identified in the Bacillus subtilis spore inner membrane fraction.

Table S2: Proteins identified in the Bacillus subtilis vegetative cell membrane fraction.

Table S3: Proteins identified in at least two replicates of the Bacillus subtilis spore inner membrane fraction and membrane protein predictions. 
Table S4: Proteins identified in at least two replicates of the Bacillus subtilis vegetative cell membrane fraction and membrane protein predictions.

Figure S1: Subcategorization of proteins according to SubtiWiki.

Figure S2: Mass distribution of identified proteins in three replicates of the spore inner membrane fraction.

Figure S3: Electron micrograph of the negatively stained Bacillus subtilis spore inner membrane fraction.

Figure S4: Electron microscopic analysis of spores during the procedure of the Bacillus subtilis spore inner membrane isolation. 

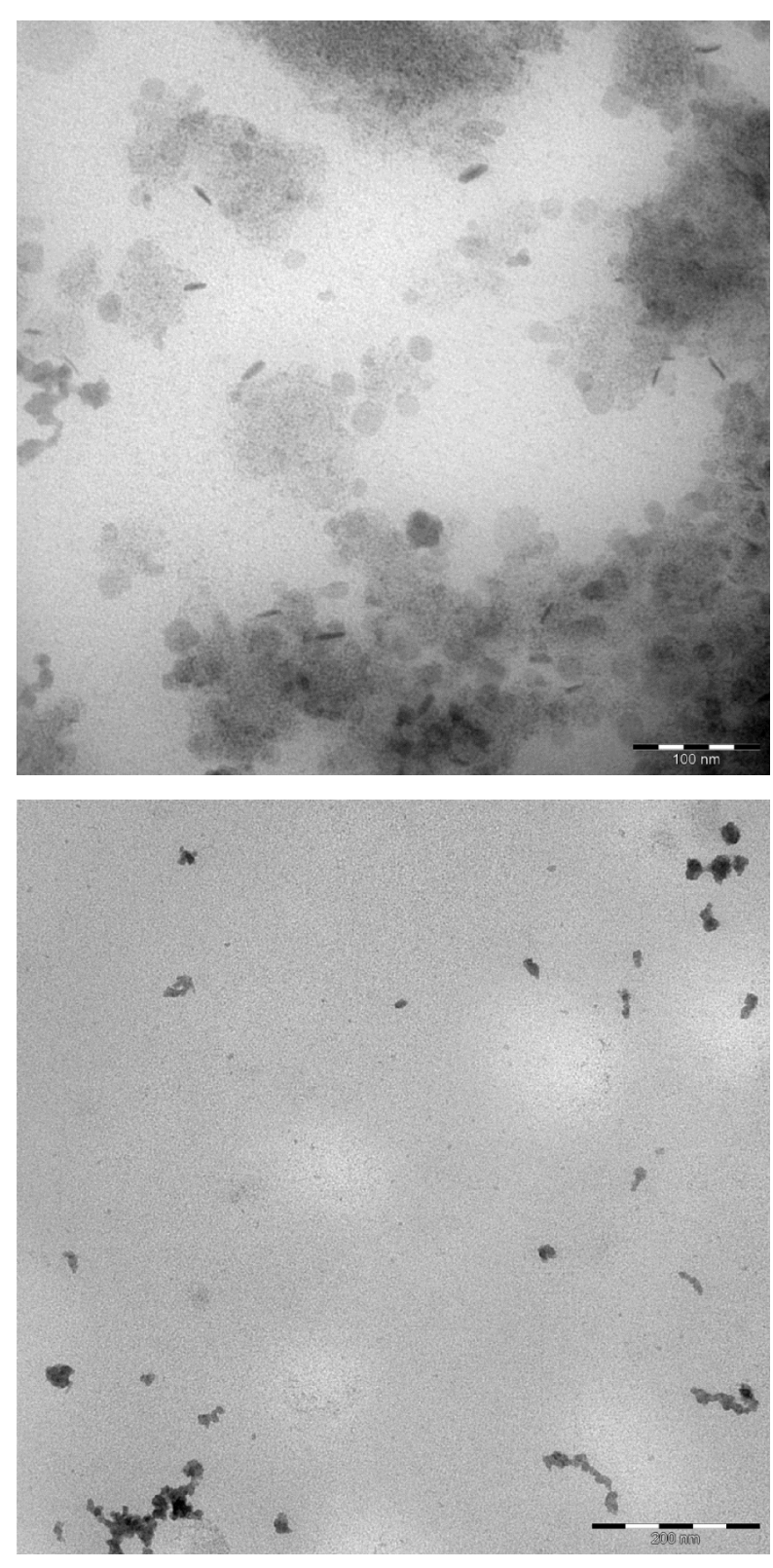

Inner membrane fraction

$\mathrm{H}_{2} \mathrm{O}$ control

Figure S3. Electron micrograph of the negatively stained Bacillus subtilis spore inner membrane fraction. The bar indicates the magnification. 
A

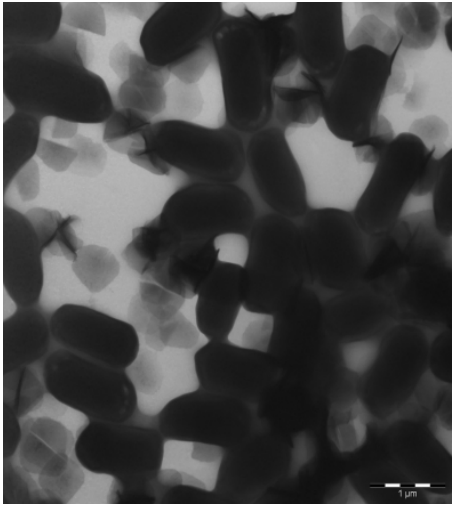

B
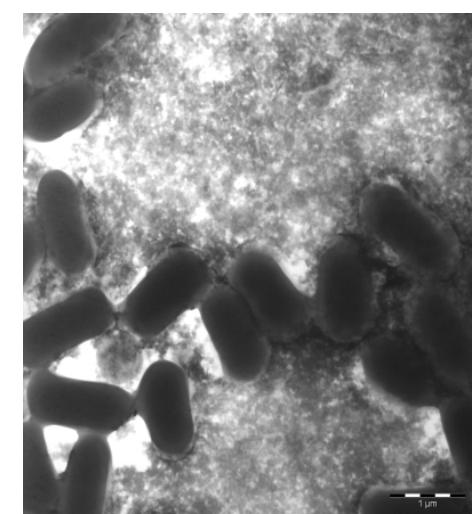

C

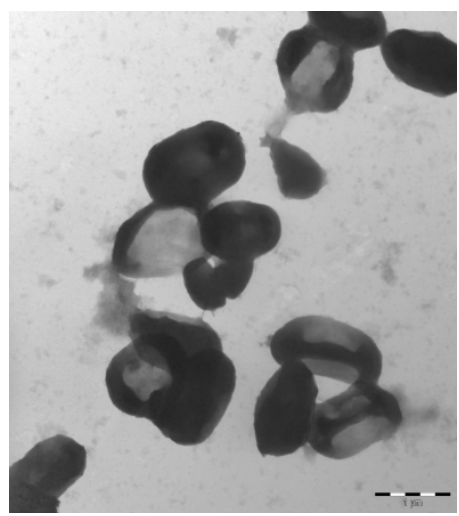

D

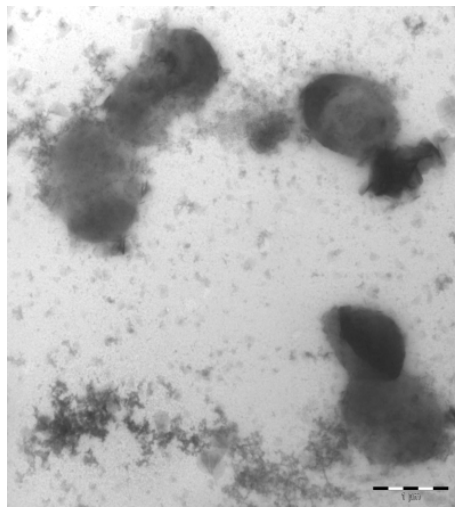

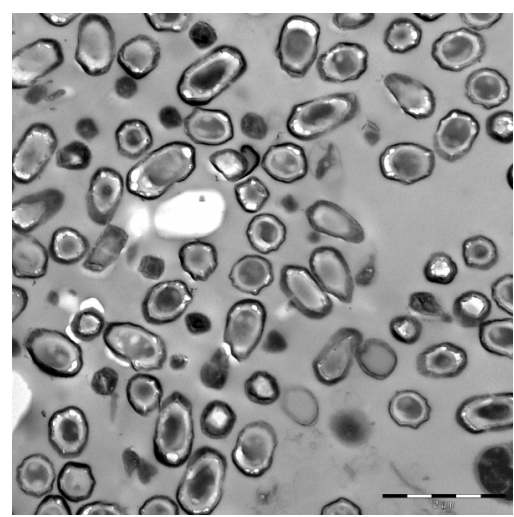
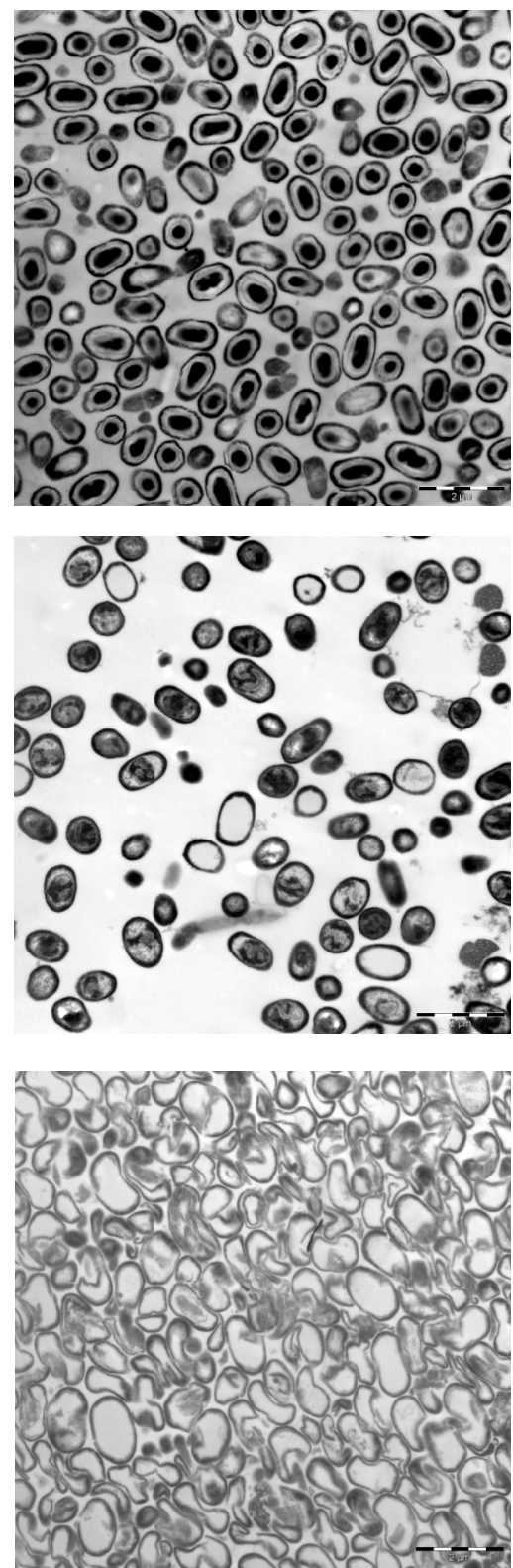
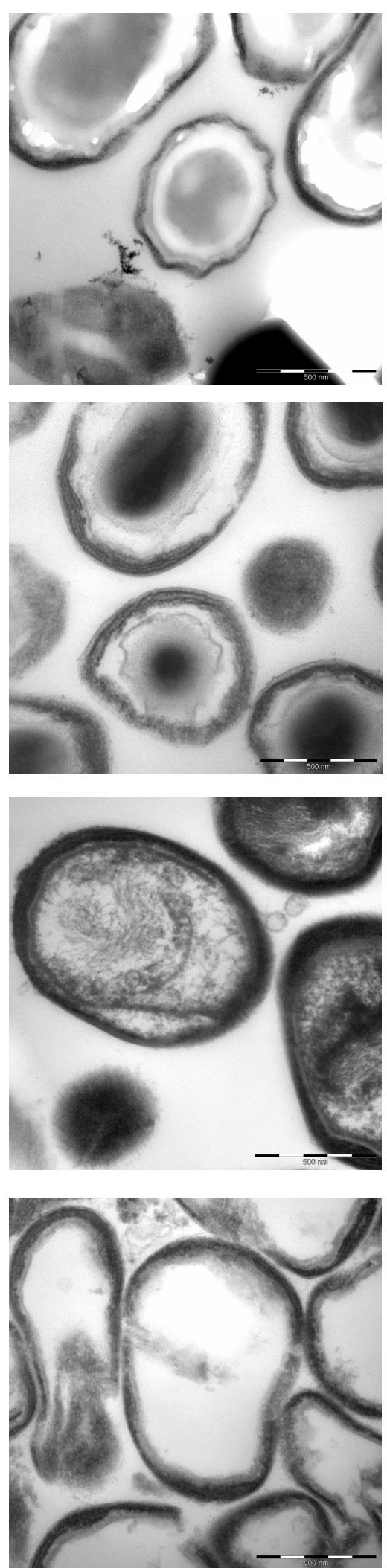

Figure S4. Electron microscopic analysis of spores during the procedure of the Bacillus subtilis spore inner membrane isolation. The left panel shows negatively stained spores. The right two panels show low and higher magnification of the sectioned samples. The bar indicates the magnification. (A) whole spores, (B) decoated spores, (C) cortex-degraded spores, and (D) integument pellet. 